\title{
PRODUÇÃO TEXTUAL ARGUMENTATIVA: PRESENÇA DAS INFORMAÇÕES MIDIÁTICAS NAS DISSERTAÇÕES DE ALUNOS DO ENSINO MÉDIO
}

\section{Argumentative textual production: presence of media information in high school students' dissertations}

\section{Produção textual argumentativa: presencia de las informaciones mediaticasen las disertaciones de estudiantes secundarios}

\author{
Elias José Mengarda ${ }^{1}$ \\ Daniela Cristina Peiter Tondolo ${ }^{2}$ \\ Francieli Aparecida Traesel $^{3}$
}

\begin{abstract}
RESUMO
Os meios de comunicação são presença rotineira na vida de grande maioria das pessoas. As novas tecnologias evoluem de modo acelerado e nos proporcionam novos formatos de mídia e de textos. Essa influência que a inserção na sociedade da informação exerce sobre as pessoas, sobretudo para os mais jovens, constitui-se num desafio imenso para todos os que atuam na área da educação. Os jovens são o segmento que mais procura, sobretudo na internet, os mais diversos tipos de informação. Por isso, a questão que motivou esse estudo trata dos modos e estratégias de como os conteúdos informacionais são processados e transformados em conhecimento pelos alunos de terceiro ano do Ensino Médio, participantes da atividade de extensão com oficinas de texto dissertativo-argumentativo, no período de agosto a novembro de 2010. Além disso, nos preocupamos com a questão da leitura, ou seja, como as ideias veiculadas pela mídia impressa e digital são assimiladas, refletidas e questionadas pelos alunos e, finalmente, como são traduzidas em conhecimento argumentativo na sua produção textual.

Palavras-chave: leitura; meios de comunicação; informatividade; argumentação; conhecimento.
\end{abstract}

\begin{abstract}
The means of communication are routine presence in the majority of people's life. The new technologies develop in high speed, providing us with new media and text formats. The influence that the information society exercises over people, especially the youngest, consists of a huge challenge for all who performs in the education field. The young people are the segment that most search for all kinds of information, especially on the internet. That is why the question that motivated this study deals with how the manners and strategies of the informational contents are processed and transformed to knowledge by the students of the high school in the third grade, participants of the extension activity with dissertative-argumentative textual workshops, in the period of August to November in 2010. Besides, we concern about the reading, that is, how the ideas exposed by the press and digital media are assimilated, reflected and questioned by the students and finally how they are translated to argumentative knowledge in their textual production. Keywords: reading; means of communication; informativity; argumentation; knowledge.
\end{abstract}

\footnotetext{
1 Universidade Federal de Santa Maria, Campus Frederico Westphalen. Centro de Educação Superior Norte - RS, BR 386, Km 40, Linha 7 de Setembro, Frederico Westphalen, Cep 98400-000, Telefone (55) 3744-8700. E-mail: mengarda@smail.ufsm.br.

2 Graduanda do $7^{\circ}$ semestre de Comunicação Social, Hab. Jornalismo.

3 Graduanda do $7^{\circ}$ semestre de Comunicação Social, Hab. Jornalismo.
} 


\section{RESUMEN}

Los medios de comunicación están presentes en el cotidiano de la vida de una gran mayoría de las personas. Las nuevas tecnologías evolucionan de forma muy acelerada y nos proporcionan nuevos formatos de mídia e de textos. Esa influencia que la inclusión en la sociedad de la información ejerce sobre las personas, principalmente a los más jóvenes, constituye un gran desafío para todos los que actúan en el área de educación. Los jóvenes son el segmento que más busca, especialmente en el internet, los más diversos tipos de información. Por eso, el asunto que motivó este estudio, trata de los modos y estrategias de cómo los contenidos informacionales son procesados y transformados en conocimiento por los alumnos del tercer curso de la enseñanza media que participan de la actividad de extensión con talleres sobre texto disertativoargumentativo durante el periodo de agosto a noviembre de 2010. Además de eso, nos preocupamos con el tema de la lectura, o sea, como las ideas vehiculadas por la mídia impresa y digital son asimiladas, reflexionadas y cuestionadas por los alumnos y, finalmente, traducidas en conocimiento argumentativo en la producción textual.

Palavras-clave: lectura; medios de comunicación; informatividad; argumentación; conocimiento

\section{Introdução}

No mundo globalizado do século XXI a sociedade encontra-se dependente da transmissão de informações. Muitas são as tecnologias que facilitam a ligação entre pontos distintos do planeta. Nesse contexto, a mídia é presença constante, quase que obrigatória na vida dos indivíduos sociais, que para interagir com os demais se utilizam de conteúdos absorvidos por meio dos veículos de comunicação. Neste artigo, tendo presente essa realidade complexa e a dinâmica dos meios de comunicação de massa, pretende-se averiguar de que maneira os alunos de terceiro ano do Ensino Médio se apropriam das informações veiculadas pelo rádio, televisão, internet, veículos impressos etc., na construção do pensamento crítico e da produção textual argumentativa em sala de aula.

Este ensaio é resultado da realização de um Projeto de Extensão, intitulado Projeto Escrever oferecido de forma gratuita entre o período de agosto a novembro de 2010 , na Escola Estadual Técnica José Cañellas de Frederico Westphalen, promovido pelas alunas Daniela C. P. Tondolo e Francieli A. Traesel, do $6^{\circ}$ semestre do Curso de Comunicação Social - Hab. Jornalismo, do campus da Universidade Federal de Santa Maria, em Frederico Westphalen, sob a orientação do professor Dr. Elias José Mengarda.

O Projeto Escrever, destinado a alunos da terceira série do Ensino Médio, trabalhou com oficinas de texto e aulas expositivas sobre argumentação sob a perspectiva da Pragmática da Comunicação, ou seja, ensinando a argumentar pensando no uso dos elementos gramaticais com interesse no efeito que eles produzem no leitor ao decodificar a mensagem. Essa perspectiva elimina o objetivo em simplesmente classificar elementos como conjunções, advérbios e orações, exercitando a partir da escolha das palavras, a linguagem como ação.

Alguns dos conteúdos ministrados nos encontros semanais trouxeram noções do uso dos operadores argumentativos, intertexto, coesão e coerência textual, modos de referenciação e progressão textual (KOCH, 2006; 2007), tipos, gêneros textuais e critérios de avaliação textual (MARCUSCHI, 2008) e tipos de parágrafos de texto dissertativo (COIMBRA, 2004) foram moldadas nas aulas com ênfase na produção de dissertações no formato exigido pelos exames vestibulares.

A partir desse contexto, debruçamo-nos sobre uma amostra de textos com o objetivo de analisar de que forma esses alunos empreendem o intertexto oriundo de conteúdos divulgados pela mídia, na construção da argumentação textual. Além disso, vamos verificar em que medida eles conseguem pôr em prática os tipos de conhecimentos citados por Koch (2006) e Koch 
e Elias (2007) para aprimorar a escrita formal. Os tipos de conhecimento a que nos referimos são os seguintes: conhecimento linguístico, conhecimento enciclopédico e conhecimento interacional.

Sabemos que os meios de comunicação proporcionam uma variedade imensa de conteúdos e nos mais variados formatos, diariamente. Desse modo, o material usado para análise neste ensaio são textos produzidos por alunos participantes do projeto e um questionário devidamente respondido. Esse questionário contribuiu para diagnosticar que tipos de mídia são utilizados pelos sujeitos sondados.

As discussões aqui propostas baseiam-se nos "três grandes sistemas de conhecimento" explicitados por Koch e Elias (2007), já citados no parágrafo anterior. Enfatizamos a importância dos sete critérios de avaliação textual propostos por Marcuschi (2008), contudo, em nossa análise, daremos enfoque primordial ao critério da "informatividade". A amostra de textos selecionada passou pelo crivo dessas teses a fim de verificar a presença ou não da mídia nos textos produzidos, a qualidade das informações expostas, a capacidade crítico-argumentativa e a exploração dos conhecimentos apreendidos pelos alunos ao elaborarem seus textos.

Destaque-se que a construção textual, nesse caso, refere-se à produção da dissertação enquanto formato linguístico já consagrado em nível acadêmico e utilizado nas provas de vestibular como processo seletivo. No entanto, o entendimento do texto, enquanto leitura, trabalhado e exigido durante as aulas do Projeto Escrever refere-se a uma concepção dialógica da língua, como é definido em Koch e Elias:

Nessa perspectiva, o sentido de um texto é construído na interação texto-sujeitos e não algo que preexista a essa interação. A leitura é, pois, uma atividade interativa altamente complexa de produção de sentidos, que se realiza evidentemente com base nos elementos linguísticos presentes na superfície textual e na sua forma de organização, mas requer a mobilização de um vasto conjunto de saberes no interior do evento comunicativo (KOCH; ELIAS, 2007, p. 11).

De fato, a leitura deve ocorrer de forma interativa, onde o sujeito recebe informações $e$ com sua carga de conhecimentos possa transformá-las em conteúdo para a construção de um pensamento crítico. Desse modo, entende-se que não há como desconsiderar a presença dos meios de comunicação, sobretudo na área da educação. As tecnologias de informação são uma realidade cada vez mais constante na vida dos jovens, e elas precisam ser bem compreendidas para que seu uso seja construtivo.

\section{A presença da mídia: leitura e produção textual}

Ao nos depararmos com um texto, seja escrito, falado, interpretado, desenhado - ou qualquer outro formato -, nos utilizamos de diversos tipos de conhecimento para interpretá-lo, afirmá-lo ou desmentir informações já interiorizadas, mas principalmente para assimilar dele novas informações. Como já foi aqui mencionado, entende-se a leitura como um processo de construção do conhecimento em que o leitor interage com o texto modificando-o à medida que o leitor/redador avança na leitura.

Com o advento das tecnologias digitais, todos estão à mercê, diariamente, dos mais variados conteúdos e formatos textuais, que emergem da tela do computador. Desse modo, como somos leitores ativos mantém-se os sentidos ocupados o tempo todo, tentando "dar conta" de processar a grande quantidade de informações que chega até nós. Porém, como as informações são muitas é preciso filtrar e selecionar o que é "melhor". Mas, o que é o "melhor"? Ou, como 
questionam os autores Fernandes e Meneguel (2008, p. 126), "o que é mostrar-se informado?"

Não há dúvida de que um dos grandes desafios da educação na atualidade é trabalhar o conhecimento com indivíduos que recebem diariamente uma carga intensa de informações provenientes dos meios de comunicação. Estimular os alunos para que filtrem os textos recebidos é com certeza uma tarefa difícil de ser administrada em termos pedagógicos.

No entanto, o problema não para nesse ponto. A interpretação dos conteúdos veiculados pelos meios de comunicação vai além da leitura, que precisa passar por um crivo ou filtro. É esse processo interpretativo que vai se refletir na produção textual dos alunos. Infelizmente, o quadro educacional no Brasil não é dos melhores, pois, de acordo com o Indicador de Alfabetismo Funcional (Inaf) de 2009, em torno de 15\% da população brasileira com idade entre 15 e 24 anos é considerada analfabeta funcional. Por isso se justificam, muitas vezes, textos com parágrafos confusos, frases soltas, informações desarticuladas e desconectadas, além da falta de habilidade em trabalhar o processo de argumentação.

Leitura, produção textual e os sistemas de conhecimento

$\mathrm{O}$ ato de leitura e a produção textual envolvem diversas atividades cognitivas. Desde o nascimento, o ser humano vai lendo o mundo ao seu redor por meio de sistemas de conhecimento, que lhe permitem interagir com o mundo $e$ tudo o que nele existe. $\mathrm{O}$ cérebro apreende as informações exteriores e as transforma em conhecimento. Para Koch e Elias (2007), o processo de leitura textual acontece de forma estratégica em nosso cérebro, tudo de maneira rápida e precisa.
Dizer que o processamento textual é estratégico significa que os leitores, diante de um texto, realizam simultaneamente vários passos interpretativos finalisticamente orientados, efetivos, eficientes, flexíveis e extremamente rápidos (KOCH; ELIAS, 2007, p. 39).

Se na leitura é assim, tanto é também a elaboração textual. Da mesma maneira que utilizamos sistemas de conhecimento para interpretar o mundo que nos cerca, da mesma forma, utilizamos estes sistemas para transmitir informações. É óbvio que tudo isso de maneira "extremamente rápida", como afirma Koch e Elias (2007). De acordo com Koch e Elias (2007) recorremos a três sistemas de conhecimento para o processamento textual (leitura e escrita), são eles:

1. Conhecimento linguístico: abrange o conhecimento da língua e suas regras. Ou seja, refere-se ao conhecimento gramatical, que vai desde a decodificação das palavras (léxico) até a forma de organização das mesmas em uma sentença (sintaxe). É o conhecimento linguístico que permite a comunicação entre os membros de uma comunidade. Por exemplo, se alguém que não conhece a língua inglesa se depara com um texto todo escrito em inglês, não haverá comunicação, pois o texto não fará sentido para esta pessoa. Mas, por outro lado, se essa mesma pessoa pegar um texto escrito na língua de sua comunidade, apenas com algumas expressões em inglês difundidas no seu grupo, o texto será compreendido.

2. Conhecimento enciclopédico: diz respeito ao conhecimento de mundo, a carga mental de cada indivíduo a respeito dos eventos sociais. Esse conhecimento possibilita ao indivíduo a capacidade de localizar cada informação no tempo $e$ no espaço, atribuindo-lhe sentido a cada informação. Por exemplo, uma pessoa que não sabe nada a respeito do atentado as Torres Gêmeas nos Estados Unidos em 2001 não compreenderia a expressão " 11 de setembro", pois ela se encaixa 
num contexto histórico desconhecido até aquele momento pelo indivíduo.

3. Conhecimento interacional: engloba as formas de interação por meio da linguagem sendo assim sintetizadas:

a. ilocucional: o conhecimento ilocucional diz respeito ao reconhecimento de conteúdos que estão colocados por trás da palavra explícita. Refere-se à produção e reconhecimento de intenções, propósitos de fala, concretizados na linguagem exposta.

b. comunicacional: refere-se ao conhecimento da quantidade necessária a ser transmitida numa dada interação comunicacional, bem como a variação linguística e o gênero textual mais adequado. Por exemplo, um palestrante sabe que deve usar a língua padrão diante de uma plateia de graduados, sem, ao mesmo tempo, exagerar na formalidade. Ou ainda, um colunista ao escrever para um jornal, sabe que deve utilizar a língua padrão para atingir o público ao qual se dirige. c. metacomunicativo: é o uso de sinais de destaque na comunicação, produzidos com intenção de facilitar a comunicação. Na comunicação falada, estes sinais são marcados por gestos $e$ a própria entonação das palavras, além das expressões faciais. Já na comunicação escrita, estes sinais são marcados pela pontuação adequada tais como: travessão, aspas, exclamação etc. para transmitir a informação. Por exemplo, se a intenção é produzir um alerta, um ponto de exclamação costuma funcionar de modo adequado.

d. superestrutural: refere-se ao reconhecimento $e$ distinção dos gêneros textuais e, paralelamente, a função que cada qual representa socialmente. Cada texto tem sua função de ser, reconhecer essa função, antes mesmo de interpretar o conteúdo do texto, facilita o entendimento do mesmo, isso porque, antes das ideias que traz, o texto já tem um significado pelo gênero que ocupa.

\section{O texto $e$ a informatividade}

Todo texto, ao ser construído, contém um propósito comunicativo. Ao falarmos ou escrevermos, temos intenção de levar uma informação a alguém (ns). No dicionário, a palavra informação deriva do verbo informar e é assim definida: "dar informações a alguém e/ou a respeito de; avisar; dar parecer sobre". Neste ensaio, ao estudar o uso da linguagem na produção dissertativa, cabe melhor a terceira definição: dar parecer sobre. Para Marcuschi (2008, p. 132) essa concepção de que informação é diferente de conteúdo precisa estar bem clara: "A informação é um tipo de conteúdo apresentado ao leitor/ ouvinte, mas não é algo óbvio".

Marcuschi (2008) ao propor os sete critérios de textualidade, considera-os essenciais para produção/avaliação textual, enfatizando a informatividade como um dos quesitos importantes. Para esse autor, a informatividade é apresentada como um critério fundamental que não pode ser confundido com quantidade de informação no texto, mas sim como qualidade de informação. Esta se relaciona diretamente com o grau de certeza que o autor proporciona ao trazer uma informação em sua fala/escrita. Dessa forma, a informatividade não se refere à quantidade de conteúdos abordados no texto, mas em relação à certeza de como o autor fala/ escreve sobre determinado tipo de informação.

O critério da informatividade é tido como fundamental, sobretudo ao se falar em dissertação que é um gênero textual opinativo. Não há outra finalidade esperada do texto argumentativo a não ser a possibilidade de convencer o leitor/ouvinte a respeito da informação que está sendo transmitida, por isso a necessidade desta ser incisiva. 


\section{Procedimentos metodológicos}

Para esta análise foram selecionadas dezoito dissertações do Projeto Escrever. Foram escolhidos três participantes do Projeto que obtiveram mais de $85 \%$ de frequência e de cada um deles foram selecionadas seis redações, sobre o mesmo tema. Nomeou-se cada participante selecionado por um código: Participante A (PA), Participante $\mathrm{B}(\mathrm{PB})$ e Participante C (PC).

Com base nos estudos propostos por Koch e Elias (2007) e Marcuschi (2008) foi criada uma tabela de avaliação, considerando quatro itens: a) Conhecimento linguístico; b) Conhecimento enciclopédico; c) Conhecimento interacional e d) Informatividade.

Cada um desses itens foi avaliado por conceitos em ordem crescente: Ruim < Regular $<$ Bom < Excelente. Para obter uma média numérica atribuímos valores aos conceitos, desta forma: Ruim = 2,5; Regular $=5 ;$ Bom $=7,5$; e Excelente $=10$. Com essa avaliação foi possível diagnosticar a quantidade de informações utilizadas pelos participantes e a qualidade da sua produção textual, tendo em vista informações disseminadas na mídia, bem como o uso de conhecimentos para a produção textual.

Os seis temas propostos para a prática da dissertação são assuntos em pauta na mídia, e, logo, na sociedade. Foram eles: Violência doméstica; Características da vida na terceira idade no século XXI; Igualdades de gênero na sociedade; Pesquisas eleitorais; Crescimento populacional e planejamento urbano; Novelas: realidade ou ficção, qual sua influência no cotidiano?.

Os participantes $\mathrm{PA}, \mathrm{PB}$ e $\mathrm{PC}$, com participação igual ou superior a $85 \%$ foram escolhidos tendo em vista que estiveram presentes na maioria das discussões realizadas no grupo. Finalmente, utilizaram-se dados dos questionários respondidos por 13 participantes, que concluíram o projeto com $75 \%$ de frequência ou mais - recebendo o certificado do curso -, para verificar em que medida estes têm contato com conteúdos veiculados pelos meios de comunicação.

\section{Apresentação e discussão dos resultados}

\section{Desempenho do Participante A (PA)}

$\mathrm{PA}$, dentre os três alunos avaliados, foi o que alcançou nota menor (nota 150), na soma das notas das seis redações, considerando a soma dos quesitos. No entanto, apresentou a maior nota no quesito Conhecimento linguístico, na soma das médias obtidas nas seis redações (nota 40), em comparação aos demais. Entretanto, mais uma vez, sua média total, no item Informatividade foi o pior comparado aos demais participantes (nota 32,5).

A dissertação do PA que alcançou maior nota foi a proposta de redação quatro, desenvolvida sobre o tema "Pesquisas eleitorais" (nota 32,5). Nesse texto o aluno PA recebeu conceito excelente no quesito Informatividade. $\mathrm{O}$ trecho abaixo mostra que PA desenvolveu uma ideia, tornando-a um argumento consistente, obedecendo ao critério da Informatividade:

PA - Trecho do texto quatro: "Nas últimas eleições elas vêm sendo usadas por partidos e coligações ajudando no planejamento estratégico de suas campanhas e por financiadores ajudando-os a decidir em qual candidato seu investimento renderá bons frutos no futuro. As pesquisas serão, portanto, como uma estimativa do que será a eleição".

Nesse trecho o PA utiliza dois argumentos no primeiro período que fortalecem a afirmação feita na última frase, dando consistência a informação apresentada. Porém, ele deixa a desejar no item Conhecimento Linguístico no primeiro período por falta de uso de vírgulas ou 
até mesmo de um conector mais apropriado para a frase. Ele comete ainda outro erro no início do segundo período ao usar a palavra "serão", quando deveria ter usado "são".

Já o texto que recebeu menor média foi a redação de número três sobre o tema "Igualdades de gênero na sociedade" (nota 17,5). Nessa dissertação, o mesmo quesito avaliado como excelente na redação sobre pesquisas eleitorais, agora recebeu o conceito ruim. Vejamos um trecho: nados, estavam aparecendo continuamente nas mais diversas mídias, em virtude das eleições de 2010. O fato de o assunto estar sendo explorado todos os dias na mídia é pertinente para justificar a melhor pontuação do PA na dissertação. Se deve considerar ainda que, além de o assunto estar sendo explorado pelos meios de comunicação, também gera discussões nos grupos de convivência.

A tabela a seguir mostra a avaliação das seis redações do aluno PA.

\begin{tabular}{|c|c|c|c|c|c|}
\hline \multicolumn{7}{|c|}{ PARTICIPANTE A } \\
\hline Texto & $\begin{array}{c}\text { Conhecimento } \\
\text { Linguístico }\end{array}$ & $\begin{array}{c}\text { Conhecimento } \\
\text { enciclopédico }\end{array}$ & $\begin{array}{c}\text { Conhecimento } \\
\text { interacional }\end{array}$ & Informatividade & Nota \\
\hline 1 & BOM & REGULAR & REGULAR & RUIM & 20 \\
\hline 2 & REGULAR & BOM & BOM & REGULAR & 25 \\
\hline 3 & REGULAR & REGULAR & REGULAR & RUIM & 17,5 \\
\hline 4 & BOM & BOM & BOM & EXCELENTE & 32,5 \\
\hline 5 & BOM & BOM & BOM & BOM & 30 \\
\hline 6 & BOM & BOM & REGULAR & REGULAR & 25 \\
\hline Nota & 40 & 40 & 37,5 & 32,5 & T=150 \\
\hline
\end{tabular}

TABELA 1 - RELAÇÃO DAS REDAÇÕES DO ALUNO PA.

PA - Trecho do texto três: "Portanto, a desigualdade entre os gêneros de fato ocorre. Hoje em dia não existem mais trabalhos somente para mulher ou somente para homens, pois não está mais na 'moda' achar que mulher tem que ficar apenas em casa cuidando dos filhos".

O parágrafo acima, além de não trazer informatividade, por ser conflituoso nas ideias apresentadas, apresenta erros de pontuação ([...] homens pois não [..]) e de flexão de palavras ([...] ficar apenas da casa [...]).

$\mathrm{O}$ resultado mostra que o mesmo participante recebeu em uma redação o maior conceito para o quesito Informatividade e o menor conceito em outra. Essa grande diferença pode ser explicada em virtude do tema proposto para cada redação. Na redação três, sobre o tema "Igualdades de gênero na sociedade", PA recebeu a menor nota, já na redação quatro, sobre o tema "Pesquisas eleitorais" recebeu a maior nota, em comparação aos seis textos analisados. Ocorre que no momento da produção textual, as pesquisas eleitorais, e todos os assuntos relacio-

\section{Desempenho do Participante B (PB)}

O PB somou na avaliação das seis dissertações 152,5 pontos considerando que a maior média foi alcançada pelo aluno na redação dois, sobre o tema "Características da vida na terceira idade no século XXI", com nota 30. Em comparação aos quatro itens avaliados na redação, PB alcançou melhores resultados no quesito Conhecimento enciclopédico, no qual somou 42,5 pontos na soma dos seis textos. A média menor ficou no critério Conhecimento linguístico, no qual obteve 35 pontos.

O PB tem muitas falhas na construção da língua escrita. Problemas de pontuação, concordância verbal e acentuação, dentre outros. Vejamos alguns trechos:

PB - Trecho do texto seis: "As novelas remetem uma certa ajuda em que as pessoas reflitam e conheçam os problemas do mundo. Como fez a novela viver a vida da rede globo onde a atriz Aline Morais interpretou a difícil realidade de ser cadeirante". 
No parágrafo escrito por $\mathbf{P B}$, percebem-se problemas que vão desde a escolha das palavras (escreve assim como fala) até a adequação da linguagem formal. Além disso, a pontuação deixa a desejar, pela falta de vírgulas na frase.

Vejamos outro trecho, onde PB mostra ter um Conhecimento enciclopédico amplo, embora nem sempre consiga colocá-lo no papel de acordo com as normas da língua.

PB - Trecho do texto cinco: "Empregos, condições de vida digna, o sonho de um futuro melhor, motivos que levam milhares de pessoas aos grandes centros. As regiões metropolitanas seguem aumentando seus níveis populacionais, uma tendência que seguirá nos próximos anos".

As ideias trazidas pelo $\mathbf{P B}$ já estão disseminadas socialmente, pois são vinculadas através dos meios de comunicação de forma repetida. São ideias tidas como certas, inseridas no texto como um conhecimento popular. Isso significa que PB está bem informado sobre a situação social da qual faz parte, conhece o mundo que o cerca e compartilha das informações difundidas midiaticamente. No entanto, ao mesmo tempo em que $\mathbf{P B}$ alcança média 42,5 em Conhecimento enciclopédico, alcança 35 em Conhecimento linguístico. Esse resultado pode ser explicado pelo fato do PB ter contato constante com as informações provenientes dos meios de comunicação, os quais lhe proporcionam informações diversas sobre tudo que ocorre na sociedade. Porém, PB encontra dificuldades com a linguagem escrita formal, erros provenientes possivelmente da falta de leitura e exercício da prática textual. A tabela a seguir mostra a pontuação do PB nas seis dissertações analisadas.

\begin{tabular}{|c|c|c|c|c|c|}
\hline \multicolumn{7}{|c|}{ PARTICIPANTE B } \\
\hline Texto & $\begin{array}{c}\text { Conhecimento } \\
\text { Linguístico }\end{array}$ & $\begin{array}{c}\text { Conhecimento } \\
\text { enciclopédico }\end{array}$ & $\begin{array}{c}\text { Conhecimento intera- } \\
\text { cional }\end{array}$ & Informatividade & Nota \\
\hline 1 & REGULAR & BOM & REGULAR & REGULAR & 22,5 \\
\hline 2 & BOM & BOM & BOM & BOM & 30 \\
\hline 3 & BOM & REGULAR & BOM & BOG & 25 \\
\hline 4 & REGULAR & BOM & BOM & BOM & 27,5 \\
\hline 5 & REGULAR & BOM & REGULAR & REGULAR & 22,5 \\
\hline 6 & REGULAR & BOM & REGULAR & 37,5 & T=152,5 \\
\hline Nota & 35 & 42,5 & 37,5 & & \\
\hline
\end{tabular}

TABELA 2 - PONTUAÇÃO DE PB NAS SEIS DISSERTAÇÕES 
PC - Trecho do texto seis: "Muita coisa, no entanto, não é real, ou pelo menos não tão real.

Os bandidos enganam o tempo todo, os mocinhos são sempre perfeitos e seus finais são sempre perfeitos, todos felizes e se amando, quando sabemos que a justiça nem sempre acontece, e o final feliz às vezes não chega na vida real".

PC - Trecho do texto quatro: "Com as pesquisas eleitorais brigas políticas aumentam, pois os candidatos que estão perdendo se sentem ameaçados e fazem de tudo para conseguir os cargos pretendidos. Até mesmo esquecer os próprios projetos para a sociedade, e começar uma guerra de calúnias, ironias e deboches uns aos outros".

Nesse último parágrafo, em especial, PC traz uma ideia concisa, todavia, não soube conjugar adequadamente os verbos na segunda frase do período, onde os verbos no infinitivo não ficaram bem colocados. Também comete equívoco ao utilizar a palavra "aos" na expressão "uns aos outros", quando o correto seria "uns contra os outros". Abaixo, a tabela de notas alcançadas nas seis redações pelo PC: avaliados, nas seis redações, resultando em uma média geral de pontos em cada um dos quatro itens. O resultado foi: Conhecimento linguístico com total de 112,5 pontos, Conhecimento enciclopédico 132,5 pontos, Conhecimento interacional 112,5 pontos e Informatividade 115 pontos.

Os textos e as notas obtidas nos critérios avaliados mostram que os participantes apresentam bom nível de Conhecimento enciclopédico, ou seja, conhecem o mundo a sua volta, os assuntos em pauta na sociedade, assuntos estes difundidos através dos meios de comunicação.

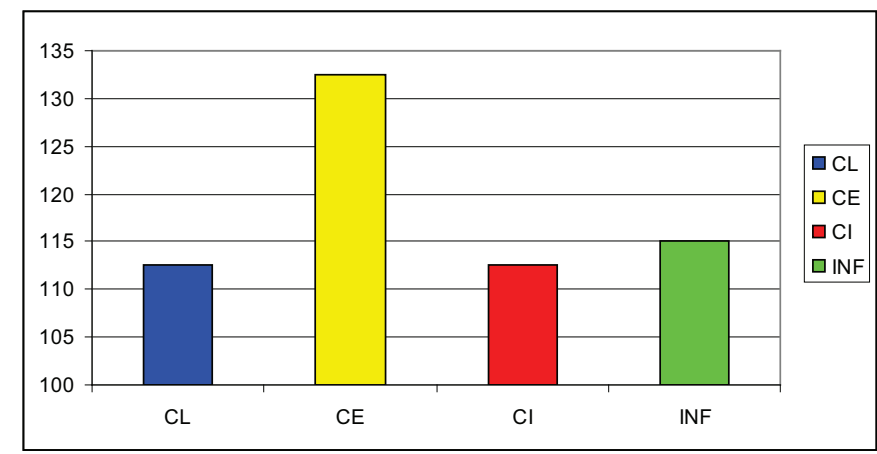

GRÁFICO 1 - SOMA DAS NOTAS OBTIDAS NOS CRITÉRIOS DE AVALIAÇÃO

\begin{tabular}{|c|c|c|c|c|c|}
\hline \multicolumn{6}{|c|}{ PARTICIPANTE C } \\
\hline Texto & $\begin{array}{l}\text { Conhecimento } \\
\text { Linguístico }\end{array}$ & $\begin{array}{l}\text { Conhecimento enci- } \\
\text { clopédico }\end{array}$ & $\begin{array}{c}\text { Conhecimento intera- } \\
\text { cional }\end{array}$ & Informatividade & Nota \\
\hline 1 & BOM & $\mathrm{BOM}$ & $\mathrm{BOM}$ & BOM & 30 \\
\hline 2 & REGULAR & BOM & BOM & $\mathrm{BOM}$ & 27,5 \\
\hline 3 & REGULAR & EXCELENTE & REGULAR & $\mathrm{BOM}$ & 27,5 \\
\hline 4 & BOM & EXCELENTE & BOM & $\mathrm{BOM}$ & 32,5 \\
\hline 5 & $\mathrm{BOM}$ & $\mathrm{BOM}$ & REGULAR & $\mathrm{BOM}$ & 27,5 \\
\hline 6 & REGULAR & $\mathrm{BOM}$ & REGULAR & $\mathrm{BOM}$ & 25 \\
\hline Nota & 37,5 & 50 & 37,5 & 45 & $\mathrm{~T}=170$ \\
\hline
\end{tabular}

TABELA 3 - CONCEITOS OBTIDOS PELO SUJEITO PC.

\section{Média geral dos critérios de avaliação}

Foram somadas as notas obtidas por cada participante em cada um dos critérios
A redação quatro, sobre o tema "Pesquisas eleitorais" foi a mais bem pontuada na soma dos quatro quesitos para o PA e PC, e, segunda melhor redação do PB. No momento da produção desses textos, havia campanha eleitoral para as eleições de 2010. Ou seja, o assunto era batido dia e noite, nos mais diversos meios de comunicação, em forma de texto escrito, texto falado, imagens, 
músicas etc. Isso mostra que, os estudantes se apropriam sim de conteúdos da mídia para construir seu pensamento crítico, para aumentar seu contingente de informações. Quanto mais um assunto é discutido na mídia, mais argumentos são apropriados ao discurso dos estudantes. Porém, é importante perceber que, apesar de os participantes utilizarem esses conteúdos de mídia, nem sempre conseguiram argumentar sobre os mesmos, já que a pontuação geral (soma dos três participantes) no critério Informatividade foi de 115 pontos.

\section{Conclusão}

Os treze participantes do Projeto Escrever (que obtiveram $75 \%$ de frequência ou mais) responderam a um questionário em que consta que 10, dos treze alunos têm acesso à internet em casa, e os demais na escola, casa de amigos e lan house. Além disso, doze deles lêem jornais impressos frequentemente. Ou seja, estão em contato direto com as informações em nível local, estadual, nacional $e$ internacional.

A avaliação por meio dos critérios Conhecimento linguístico, Conhecimento enciclopédico, Conhecimento interacional e Informatividade possibilitaram verificar que as maiores dificuldades dos alunos encontram-se nos critérios Conhecimento linguístico e Conhecimento interacional, que se referem ao uso da língua formal. O primeiro diz respeito às normas gramaticais e o segundo, às adequações pragmáticas do texto, ou seja, relaciona-se aos artifícios ou estratégias de interação inseridos no texto.

Outro critério que revela defasagens nas dissertações avaliadas é o da Informatividade, que se refere à qualidade das informações presentes no texto. Ao mesmo tempo que os participantes mostraram bom conhecimento enciclopédico, nem sempre souberam construir novas informações, novos argumentos a partir das informações já existentes, oferecidas pela mídia. A falta de argumentação acontece em virtude da mera recepção de conteúdos, feita sem análise crítica - ao menos, não demonstrada nos exercícios realizados em grupo.

Com esse resultado, fica clara a necessidade de trabalhar com os alunos os textos veiculados pela mídia. Os meios de comunicação oferecem um conteúdo riquíssimo sobre as mais diversas áreas de conhecimento, sobre os mais variados assuntos da pauta social, mas faz-se necessário que esses textos sejam discutidos e estudados a fundo para que a leitura gere novos conhecimentos. Somente essa prática recorrente pode melhorar os resultados obtidos nessa análise.

Hoje, educação e comunicação não podem mais andar separados. A escola não pode prescindir da presença da mídia, pois ela é presença diária na vida de todos os cidadãos. Refletir sobre os produtos de mídia e exercitar a produção textual é uma ação indispensável para formar alunos críticos, capazes de enfrentar sem medo o vestibular, a academia e o mercado de trabalho.

\section{REFERÊNCIAS}

COIMBRA, Oswaldo. A dupla face do texto. In: O Texto da Reportagem Impressa - um curso sobre sua estrutura. São Paulo: Ática, 2004.

FERNANDES, Fabiano Seixas; MENEGUEL, Fernando. Do Terceiro critério: medindo e avaliando níveis de informação e argumentação em redações para o Concurso Vestibular UFSC. In: FERRARO, Maria Luiza et al. (Orgs.) Experiência e prática de redação. Florianópolis: Editora da UFSC, 2008.

$\mathrm{KOCH}$, Ingedore Villaça; ELIAS, Vanda Maria. Ler e Compreender os sentidos do texto. 2 ed. São Paulo: Contexto, 2007.

$\mathrm{KOCH}$, Ingedore Villaça. Argumentação e linguagem. 10 ed. São Paulo: Editora Cortez, 2006.

MARCUSCHI, Luiz Antônio. Produção textual, análise de gêneros e compreensão. 2 ed. São Paulo: Parábola Editorial, 2008.

SILVA, Michele. Uma lenta Caminhada para vencer o analfabetismo funcional. Disponível em: <http://revistaescola.abril.com.br/politicas-publicas/avaliacao/umalenta-caminhada-analfabetismo-funcional-alfabetismoinaf-instituto-paulo-montenegro-leitura-escrita-518768. shtml>. Acesso em: 08/2/2011. 